\title{
Simulation and Experimental Research on Electrical Control Anti-backlash Based on a Novel Type of Variable Tooth Thickness Involute Gear Pair
}

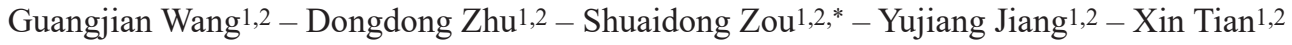 \\ 1 Chongqing University, State Key Laboratory of Mechanical Transmissions, China \\ ${ }^{2}$ Chongqing University, College of Mechanical and Vehicle Engineering, China
}

This paper presents an electrical backlash control method based on a novel variable tooth thickness involute gear pair (VTTIGP) through acceleration judgment. First, the principle, characteristics and theoretical tooth surface equation of the novel type of variable tooth thickness involute gear (VTTIG) are proposed. Compared with the traditional variable tooth thickness gear (VTTG), each transverse of the novel type of VTTIG has the same tooth root circle and the addendum circle. Therefore, there will be no interference caused by the excessive axial relative movement distance between the gear pairs when eliminating the backlash. The theoretical calculation equation of no-load transmission error (TE) and time-varying backlash for a dual-eccentric novel type of VTTIGP are deduced. Second, using the theoretical backlash equation and the eccentricities and the initial phases obtained through the experimental TE curve obtained with angular displacement sensors and the developed TE equation, the continuous backlash curve of the gear pair is obtained. Based on the RecurDyn software and its Colink control module, the co-simulation model of the novel type of VTTIGP and its backlash control system is used to explore the electrical backlash control method through acceleration judgment in the case of time-varying backlash. Finally, using angular displacement sensors and linear actuators, the experimental study on the anti-backlash control with different reversed positions under different input speeds is carried out, demonstrating that this novel electrical anti-backlash control method is effective.

Keywords: anti-backlash, electrical control, time-varying backlash, transmission error, variable tooth thickness gear pair

Highlights

- An electrical backlash control method based on the new type of VTTIGP through acceleration judgment is proposed.

- The principle, characteristics, and theoretical tooth surface equation of the novel type of VTTIG are proposed.

- The formula of the non-load TE and time-varying backlash based on the eccentricity error model of the novel type of VTTIG is derived.

- The simulation and experiment further verify the effectiveness of the electrical anti-backlash control method based on acceleration judgment.

\section{O INTRODUCTION}

Gear transmission is widely used in precision servo transmission systems, such as robots, machine tools and tracking and positioning systems, which require fast responses, high positioning accuracy, and good stability [1] and [2]. However, gears will cause errors in the process of machining and assembly, and these errors often affect the backlash of the gear transmission process [1] and [3]. Gear backlash is a nonlinear factor affecting gear performance [4]. For a reciprocating system, the non-linearity of the gear tooth backlash will directly affect the stability, accuracy, and sensitivity of the servo control, resulting in delay and discontinuity of the output motion response [5] to [8]. Therefore, adjusting and controlling the gear backlash is of great significance to improve the accuracy of the transmission system. In practical applications, it is necessary to adopt special anti-backlash mechanisms and technical measures to eliminate backlash when the machining and assembly accuracy reaches a certain level [9] and [10]. Research on gear anti-backlash has always been a topic of great interest, and various methods of anti-backlash exist. Generally speaking, the commonly used anti-backlash methods include adjustable centre distance, springloaded gears, fixed split gears, and adjustable tooth thickness gear [10] and [11].

The variable tooth thickness gear, also known as the beveloid gear, which was first proposed by Beam in 1954 [12], has become an important gear drive for power and motion transmission due to its advantages, such as abilities to backlash control, misalignments absorption, and easy manufacturing. It is widely used for precision transmission, such as rotate vector (RV) reducer, microscope gear, and others [13] and [14]. In recent years, people have conducted extensive research on the geometric design, meshing characteristics and applications of VTTG. Do et al. [15] modelled and simulated the variable-thickness gear transmission. Based on the hob-machining theory, Yang et al. [16] established a mathematical model of the tooth surface 
of a VTTG considering the machine tool adjustment errors. Cao et al. [17] proposed a plunge-shaving model for variable tooth thickness based on ordinary gearshaving machine tools' structure. Brauer [18] used a global-local FE approach to study the transmission error of VTTG. Song et al. studied the meshing stiffness of VTTG pairs [14], [19] and [20]. Chen et al. [13] studied the contact characteristics of variablethickness internal gear transmission and the machining principle of internal variable-thickness gears. Li et al. [21] used the VTTIG as the transmission part of the robot RV reducer. Yan et al. [22] used the VTTIG as the transmission part of the $3 \mathrm{~K}$ reducer. Zheng et al. [23] and Ye et al. [24] combined VTTIG with a doublelead involute cylindrical worm and proposed a new type of worm gear with adjustable backlash. However, the above-mentioned VTTG realizes the axial change of the tooth thickness by adopting different radial modification coefficients, which makes the tooth root circle and the addendum circle of each transverse different. Therefore, interference is easy to occur during the anti-backlash process of the axial movement of the gear pair.

Among the commonly used anti-backlash methods, adjustable centre distance, fixed split gears, and adjustable tooth thickness gear only eliminate constant backlash, while spring-loaded gears are limited to light load applications. With the development of control technology, it has become increasingly common to eliminate the backlash through algorithms control or the combination of mechanical structures and algorithms control [25] to [28]. Shi and Zuo [29] proposed a "soft degree" concept and presented a backstepping algorithm to overcome the backlash non-linearity in gear transmission servo systems. For low operating speed systems with relative cyclic motion, Warnecke and Jouaneh [7] presented an approach for backlash compensation via modification of the input motion. However, this method has a high requirement for motor response, and it also has low anti-interference capability. Sato et al. [30] adopted the piezoelectric actuators to create a preload in a lead screw and nut mechanism to control and eliminate the backlash. However, it is limited to low torque and force applications. Presently, in robots, tracking and positioning systems, and computer numerical control (CNC) machine tools, the backlash is adjusted and controlled by the method of dual-motor driven electrical anti-backlash based on bias torque or speed difference [1] and [31] to [33]. However, because of the need for two sets of transmission chains, two sets of servo systems, and a backlash control card, the volume and the cost of the system are high.
In a precision transmission system, eccentricity is the main source of large-period time-varying TE and periodic time-varying backlash [1]. If the total backlash law curve, including constant backlash and periodic time-varying backlash, can be determined, the backlash can be controlled and adjusted according to the characteristics that the novel type of VTTIGP can adjust the backlash through relative axial movement. Based on this, this paper presents a method of electrical control anti-backlash based on the novel type of VTTIGP, which has a much relative smaller volume and lower cost: based on determining the continuous backlash curve of the novel type of VTTIGP, according to the acceleration change of the novel type of VTTIGP, and by adjusting the real-time position relationship between the driving gear and the driven gear of the novel type of VTTIGP, the backlash can be controlled.

The structure of this paper is as follows. First, the principle, characteristics and theoretical tooth surface equation of the novel type of variable tooth thickness gear are proposed. Then, calculation models with a theoretical no-load TE and backlash of the novel type of VTTIGP with dual-eccentricities were constructed. Next, the eccentricity and its initial phase of the experimental device were obtained by fitting the theoretical no-load TE equation and then the backlash curve of the gear pair was acquired through the backlash equation and the resultant eccentricity. Finally, according to the acquired backlash curve, and through simulation and experiment, the electrical anti-backlash control method based on acceleration judgment was verified.

\section{METHODS}

\subsection{The Novel Type of VTTIG Based on Compound Modification}

\subsubsection{The Principle and Characteristics of A New Type of VTTIG}

As shown in Figs. 1 and 2, the two tooth surfaces of the novel type of VTTIG form a certain cone angle along the gear axis. By adjusting the relative position of the meshing gears along the axis, the meshing backlash can be adjusted to realize a slight backlash or no backlash transmission. In order to facilitate the meshing backlash control of the gear pair, the novel type of VTTIG adopts a constant radial modification and a gradual tangential modification at the same time, and the tangential modification of the left and right tooth surfaces changes linearly at the same 
slope. Compared with the traditional VTTG, each transverse of the novel type of VTTIG has the same tooth root circle and the addendum circle. Therefore, no interference will be caused by the excessive axial relative movement distance between the gear pairs while eliminating the backlash.

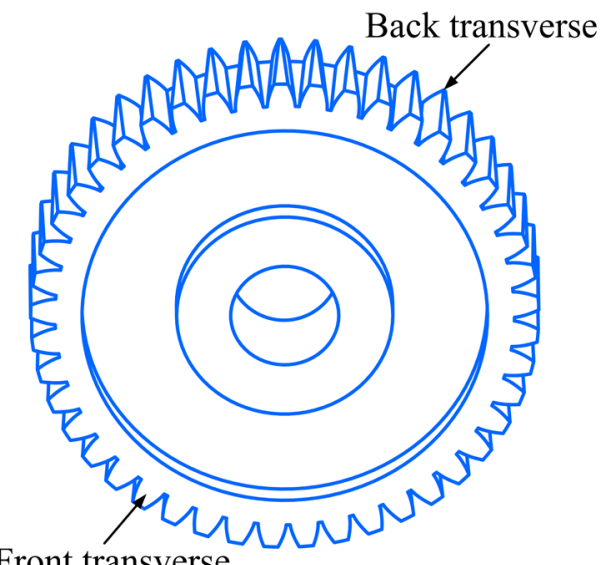

Fig. 1. The model of the novel type of VTTIG

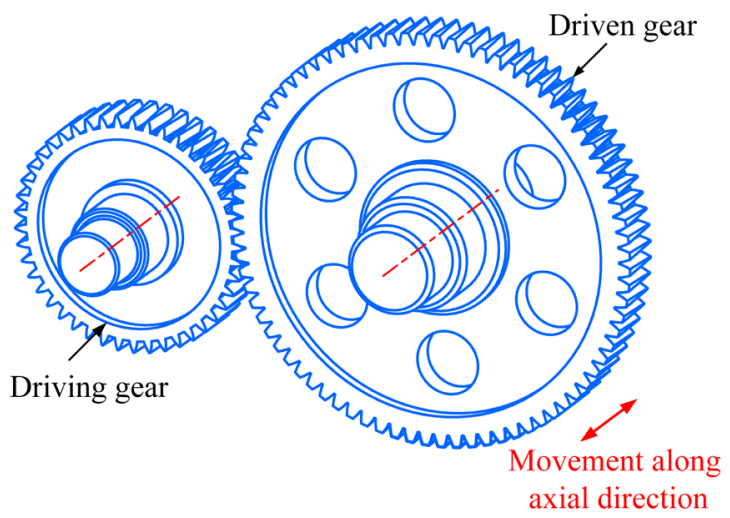

Fig. 2. The $3 D$ model of the novel type of VTTIGP

As shown in Fig. 3a, the indexing tooth thickness of the novel type of VTTIG consists of standard tooth thickness (1), radial modification coefficient increments (2), and gradually changing tangential modification coefficient increment (3). As shown in Fig. 3b, the tooth thickness of the intermediate transverse is $p$, and through tangential modification, the tooth thickness of the other transverse is $p$ plus or minus the tangential modification coefficient increment $x$. When the tangential modification coefficient changes linearly along the axial direction, the generated gear tooth surface is an involute helical surface, and the left and right tooth surfaces of the gear teeth are double helical surfaces with different helix angles or directions. At the same time, it can also be modified according to specific regular changes to form drum-shaped teeth and other teeth shapes, thereby improving the load-bearing capacity and reducing vibration, impact and noise during transmission. However, it is the most convenient to use the linearly changing tangential modification coefficient in the actual application process.
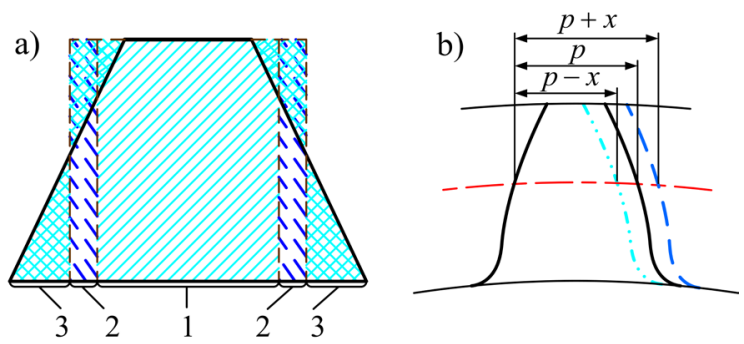

Fig. 3. The comparison of indexing circle expansion and end face; a) index circle expansion diagram, and b) tangentially modified tooth profile

\subsubsection{The Tooth Surface Equation of the New Type of VTTIG}

Litvin [34] proposed a method of generating helical gears with a pair of conjugate female surfaces. This method can be applied to the derivation of the tooth surface equation and the normal vector of any point on the tooth surface [35]. Assuming that the gear is processed by the rack cutter through the method of generating an envelope, the rigid body motion relationship is mainly considered [36], and the influence of elastic deformation is neglected. The parameters of the rack cutter are as follows, the left and right helix angles of the rack are $\beta_{R}$ and $\beta_{L}$, and the left and right helix angles of the gear can be obtained as $\beta_{L}$ and $\beta_{R}$; normal pressure angle $\alpha_{n}=20^{\circ}$, transverse pressure angle: AC transverse pressure angle is $\alpha_{a t 1 L}, \mathrm{DF}$ transverse pressure angle is $\alpha_{a t 1 R}$, and their sizes may be different; the modulus is $m$, the bottom clearance $c_{p}=0.25 m$, the addendum $h_{a p}=m$, and dedendum $h_{f p}=1.25 \mathrm{~m}$. As shown in Fig. 4, the blue contour is the rack cutter of a novel type of VTTIG with compound modification. The helix angle of the orange part is $\beta_{R}$. After tangential modification, $\beta_{L}$ is obtained by keeping the transverse pressure angle of the indexing circle unchanged.

According to the basic theorem of the Willis principle, the gear tooth profile curve and the gear cutter curve are conjugate tooth shapes. At any instant of transmission, their common normal line at the contact point must pass through the instantaneous node. Based on this, the discrete equation of the contact point $\mathrm{K}$ can be obtained. Coordinate systems 
[36] are established, as illustrated in Fig. 5. $S_{1}\left(O_{1}-\right.$ $\left.x_{1} y_{1} z_{1}\right), \quad S_{2}\left(O_{2}-x_{2} y_{2} z_{2}\right)$ and $S_{0}\left(O_{0}-x_{0} y_{0} z_{0}\right)$ are the coordinate system fixedly connected to the rack, the fixedly connected gear rotating coordinate system and auxiliary static coordinate system, respectively. $r_{2}$ and $\varphi$ are the reference pitch circle radius and the rotation angle for the processing, respectively.

In the $S_{1}$ coordinate system, the coordinate equation $\mathbf{R}_{1}^{A C}$ of the point $\mathrm{K}$ on the line segment $\mathrm{AC}$ on any transverse can be expressed as follows:

$\mathbf{R}_{1}^{A C}(d, l)=\left[\begin{array}{lll}x_{1} & y_{1} & z_{1}\end{array}\right]$
$=\left[\begin{array}{l}d \sin \alpha_{a t 1 L}+l \tan \beta_{L}-\pi m / 4-h_{a p} \tan \alpha_{a t 1 L} \\ d \cos \alpha_{a t 1 L}-h_{a p} \\ l\end{array}\right]^{\mathrm{T}}$,

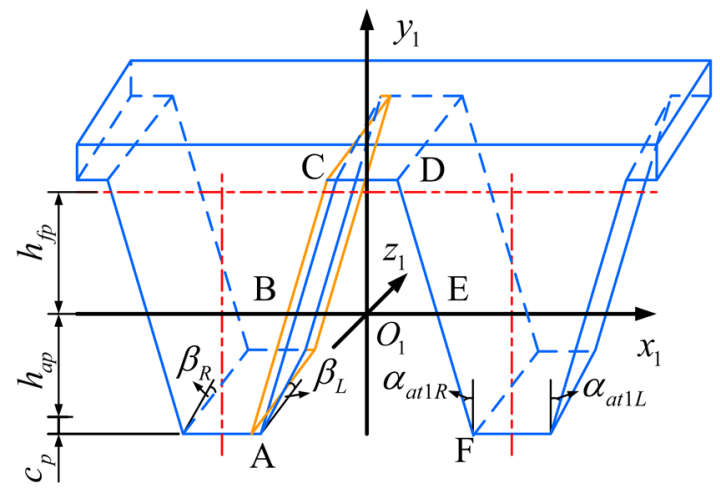

Fig. 4. The parameters of rack cutter

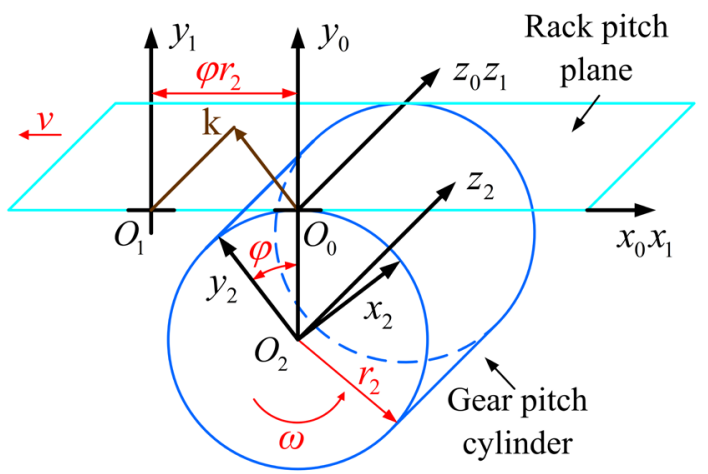

Fig. 5. Coordinate relationship of forming tooth surfaces

where $d$ is the distance from any point $\mathrm{K}$ to point $\mathrm{A}$ on the line segment $\mathrm{AC}$ on any transverse, and $l$ is the $\mathrm{Z}$ coordinate value of the studied transverse.

In the $S_{1}$ coordinate system, the coordinate equation $\mathbf{R}_{1}^{D F}$ of the point $\mathrm{K}$ on the line segment DF on any transverse can be expressed as follows:

$$
\begin{aligned}
& \mathbf{R}_{1}^{D F}(d, l)=\left[\begin{array}{lll}
x_{1} & y_{1} & z_{1}
\end{array}\right] \\
& =\left[\begin{array}{l}
-d \sin \alpha_{a t 1 R}-l \tan \beta_{R}+\pi m / 4+h_{a p} \tan \alpha_{a t 1 R} \\
d \cos \alpha_{a t 1 R}-h_{a p} \\
l
\end{array}\right]^{\mathrm{T}},
\end{aligned}
$$

where $d$ is the distance from any point $\mathrm{K}$ to point $\mathrm{F}$ on the line segment DF on any transverse, and $l$ is the $\mathrm{Z}$ coordinate value of the studied transverse.

When the rack pitch plane and the gear pitch circle roll with each other, the gear tooth surface is processed using the rack tooth surface envelope. By deriving the variables in the coordinate equation $\mathbf{R}_{1}^{A C}$ of any point on the line $\mathrm{AC}$ segment respectively, the following equations can be obtained as:

$$
\frac{\partial \mathbf{R}_{1}^{A C}}{\partial d}=\left[\begin{array}{c}
\sin \alpha_{a t 1 L} \\
\cos \alpha_{a t 1 L} \\
0
\end{array}\right], \quad \frac{\partial \mathbf{R}_{1}^{A C}}{\partial l}=\left[\begin{array}{c}
\tan \beta_{L} \\
0 \\
1
\end{array}\right] .
$$

Thus, the normal vector of the tooth surface of the $\mathrm{AC}$ segment of the basic rack can be obtained as:

$$
\mathbf{n}_{A C}=\left[\begin{array}{c}
\cos \alpha_{a t 1 L} \\
-\sin \alpha_{a t 1 L} \\
-\cos \alpha_{a t 1 L} \tan \beta_{L}
\end{array}\right] .
$$

Similarly, the tooth surface equation and normal vector of the other parts of the rack can be obtained.

According to the basic principle of gear meshing, the condition for any point $\mathrm{K}\left(x_{1} i, y_{1} j, z_{1} k\right)$ on the tooth surface to become a contact point is that the normal vector direction is perpendicular to the sliding speed direction [35]. If the sliding speed of the gear contact point $\mathrm{K}$ relative to the rack is represented by $\mathbf{v}_{1}^{12}$, the speed of the rack in the $S_{1}$ coordinate system is $\mathbf{v}_{1}^{1}$, and the speed of the gear at point K in the $S_{1}$ coordinate system is $\mathbf{v}_{1}^{2}$, the following equation can be obtained as:

$$
\left[\begin{array}{l}
\mathbf{v}_{1}{ }^{1} \\
\mathbf{v}_{1}{ }^{2}
\end{array}\right]=\left[\begin{array}{l}
-\omega r_{2} i \\
\boldsymbol{\omega} \times \mathbf{O}_{2} \mathbf{K}
\end{array}\right] .
$$

In the $S_{1}$ coordinate system, the angular velocity vector $\boldsymbol{\omega}$ and vector $\mathbf{O}_{2} \mathbf{K}$ can be expressed as follows:

$$
\begin{gathered}
\omega=-\omega k, \\
\mathbf{O}_{2} \mathbf{K}=\mathbf{O}_{2} \mathbf{O}_{0}+\mathbf{O}_{0} \mathbf{O}_{1}+\mathbf{O}_{1} \mathbf{K} \\
=\left(x_{1}-\varphi r_{2}\right) i+\left(y_{1}+r_{2}\right) j+z_{1} k .
\end{gathered}
$$

According to Eqs. (5) to (7), the equation of relative sliding speed can be obtained as:

$$
\mathbf{v}_{1}^{12}=\omega\left(\left(x_{1}-\varphi r_{2}\right) j-y_{1} i\right) .
$$


The relationship between the normal vector and relative sliding speed can be represented as follows:

$$
\mathbf{n}_{A C} \cdot \mathbf{v}_{1}^{12}=0 .
$$

According to Eqs. (4), (8), and (9), the following equation can be obtained as:

$$
y_{1}=-x_{1} \tan \alpha_{a t 1 L}+\varphi r_{2} \tan \alpha_{a t 1 L} .
$$

According to Eqs. (1) and (10), the general meshing equation of rack AC segment and gear tooth surface can be represented as follows:

$$
\begin{aligned}
& \tan \alpha_{a t 1 L}\left(d \sin \alpha_{a t 1 L}+l \tan \beta_{L}-\pi m / 4-h_{a p} \tan \alpha_{a t 1 L}\right) \\
& +d \cos \alpha_{a t 1 L}-\varphi r_{2} \tan \alpha_{a t 1 L}-h_{a p}=0 .
\end{aligned}
$$

The conversion relationship between the contact point $K$ in the gear coordinate system and the rack coordinate system can be determined by the following equation [35]:

$$
\left[x_{2}, y_{2}, z_{2}, t\right]^{\mathbf{T}}=\mathbf{M}_{21}\left[x_{1}, y_{1}, z_{1}, t\right]^{\mathbf{T}},
$$

where the matric $\mathbf{M}_{21}$ is the transformation matrix as:

$$
\mathbf{M}_{21}=\left[\begin{array}{cccc}
\cos \varphi & \sin \varphi & 0 & r_{2}(\sin \varphi-\varphi \cos \varphi) \\
-\sin \varphi & \cos \varphi & 0 & r_{2}(\cos \varphi+\varphi \sin \varphi) \\
0 & 0 & 1 & 0 \\
0 & 0 & 0 & 1
\end{array}\right] .
$$

After finishing Eq. (11), the expression of variable $d$ can be obtained as follows:

$$
\begin{gathered}
d=\sin \alpha_{a t 1 L}\left(\pi m / 4+h_{a p} \tan \alpha_{a t 1 L}\right. \\
\left.+\frac{h_{a p}}{\tan \alpha_{a t 1 L}}+\varphi r_{2}-l \tan \beta_{L}\right) .
\end{gathered}
$$

According to Eqs. (1), (12), and (13), the coordinate conversion relationship can be obtained as follows:

$$
\left\{\begin{array}{l}
x_{2}=x_{1} \cos \varphi+y_{1} \sin \varphi+r_{2}(\sin \varphi-\varphi \cos \varphi) \\
y_{2}=-x_{1} \sin \varphi+y_{1} \cos \varphi+r_{2}(\cos \varphi+\varphi \sin \varphi) . \\
z_{2}=l
\end{array}\right.
$$

According to Eqs. (1), (14), and (15), the final tooth surface equation without the intermediate parameter $d$ can be obtained. Similarly, the tooth surface equations of other parts of the gear surface can be obtained.

\subsection{The Principle and Strategy of Backlash Control for the Novel Type of VTTIGP}

The anti-backlash principle for the novel type of VTTIGP is based on the change of tooth thickness along the axial direction of gear tooth thickness. As shown in Fig. 6, backlash is controlled by adjusting the relative axial displacement between the driving and the driven gear.

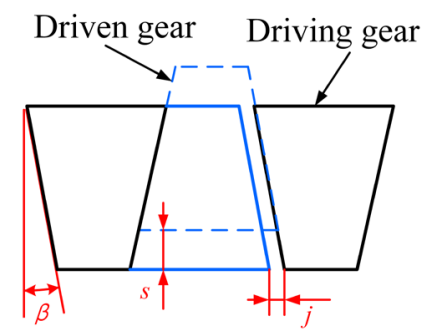

Fig. 6. Anti-backlash principle of the composite modified VTTIGP

The composite modified VTTG with left and right tooth profiles of identical tangential modification is introduced in [37], and the relationship between the axial displacement of the driven gear and the backlash can be expressed as follows:

$$
j=2 s \tan \beta,
$$

where $j$ is the backlash of the gear pair, $s$ is the axial displacement of driven gear to eliminate backlash, $\beta$ is the helix angle of the novel type of VTTIG. Therefore, the axial displacement of the driven gear required to eliminate backlash can be obtained with the known backlash.

Fig. 7 shows a flow chart of backlash adjustment based on acceleration judgment. When the gear pair is detected as beginning to decelerate, the driven gear will be driven by a linear actuator to move axially based on Eq. (16), which eliminates the backlash when the rotational direction of the gear pair reverses.

Subsequently, when the gear pair is detected speeding up, the driven gear will return to the initial axial displacement to prepare for the next backlasheliminating sequence.

\subsection{Calculation of Backlash of Gear Pair with Dual- eccentricities}

Eccentricity error is the main factor leading to largeperiod time-varying $\mathrm{TE}$ and periodic time-varying backlash. Therefore, this paper first theoretically derives the TE and time-varying backlash equations of the novel type of VTTIGP under eccentricity 


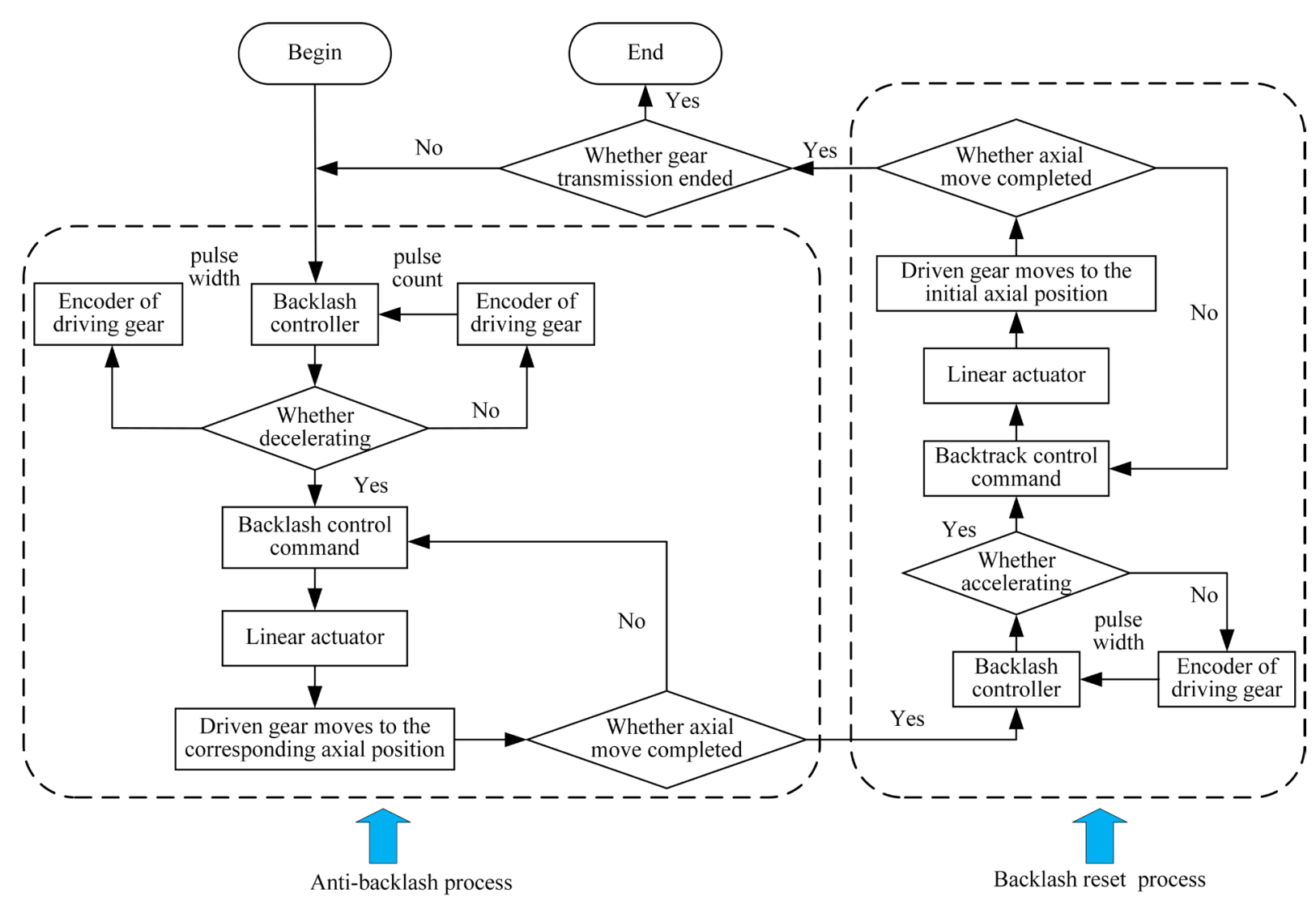

Fig. 7. Backlash control mode based on acceleration judgment

error. Then through the experimental TE curve and the derived TE equation, the eccentricity error of the novel type of VTTIGP is solved in reverse, and then the time-varying backlash curve under the gear pair eccentricity error is obtained. Finally, through the above-mentioned anti-backlash strategy, the active anti-backlash of the novel type of VTTIGP is realized.

\subsubsection{Theoretical No-Load TE Calculation}

Since each transverse of the novel type of VTTIG is an involute gear pair, the novel type of VTTIGP can be analysed according to the relevant theories of involute cylindrical gear pair. If the driving gear has an eccentricity, the meshing point displacement along the line of action will change after rotating each unit angle. Compared with the ideal gear transmission, when the driving gear rotates counter-clockwise or clockwise, as shown in Fig. 8, the displacement increment of the meshing point along the line of action can be expressed as follows [1] and [38]:

$$
\left[\begin{array}{c}
\Delta F_{1}^{1} \\
\Delta F_{1}^{2}
\end{array}\right]=e_{1}\left[\begin{array}{l}
\sin \left(\varphi_{1 c c}+\theta_{1}+\alpha\right) \\
\sin \left(\varphi_{1 c}-\theta_{1}+\alpha\right)
\end{array}\right],
$$

where $\Delta F_{1}^{1}$ and $\Delta F_{1}^{2}$ represent the displacement increment along the line of action caused by eccentricity when the driving gear rotates counterclockwise and clockwise, respectively; $\varphi_{1 c c}, \varphi_{1 c}, e_{1}$, and $\theta_{1}$ are the angular displacement along the counterclockwise direction, the angular displacement along the clockwise direction, the eccentricity, and initial phase of eccentricity of driving gear, respectively.

Similarly, if the driven gear has an eccentricity and when the driving rotates counter-clockwise or clockwise, as shown in Fig. 9, the displacement increment along the line of action can be calculated as follows:

$$
\left[\begin{array}{l}
\Delta F_{2}^{1} \\
\Delta F_{2}^{2}
\end{array}\right]=e_{2}\left[\begin{array}{l}
\sin \left(\varphi_{2 c c}+\theta_{2}-\alpha\right) \\
\sin \left(\varphi_{2 c}-\theta_{2}-\alpha\right)
\end{array}\right],
$$

where $\Delta F_{2}^{1}$ and $\Delta F_{2}^{2}$ represent the displacement increments along the line of action caused by the eccentricity when the driving gear rotates counterclockwise and clockwise, respectively; $\varphi_{2 c c}, \varphi_{2 c}, e_{2}$, and $\theta_{2}$ are the angular displacement along the counterclockwise direction, the angular displacement along 
the clockwise direction, the eccentricity, and initial phase of the driven gear, respectively.
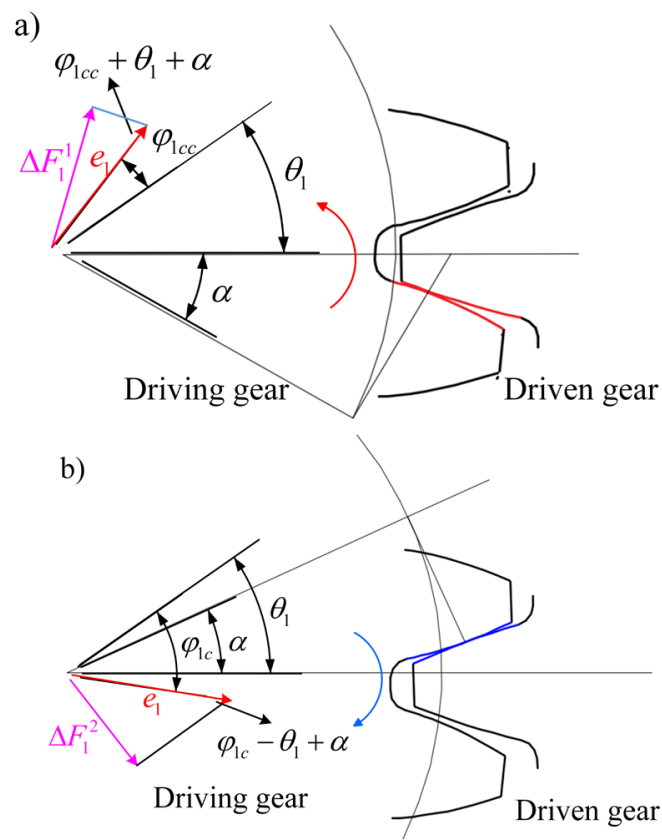

Fig. 8. Displacement increment along the line of action calculation model with the eccentricity of the driving gear at any transverse section; a) driving gear rotates counter-clockwise, and b) driving gear rotates clockwise

a)

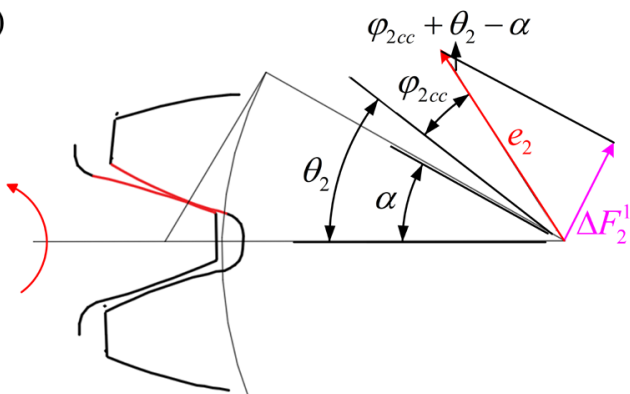

Driving gear

Driven gear

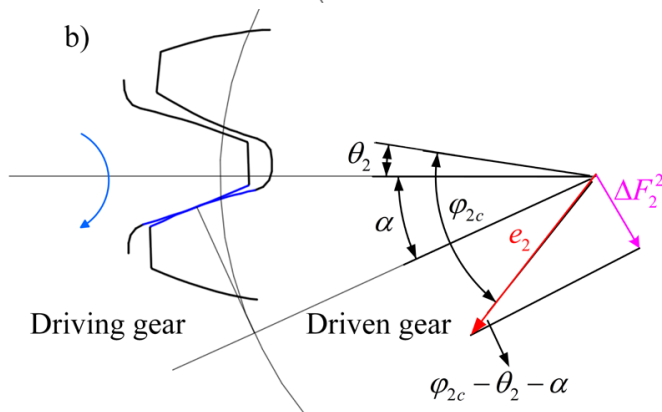

Fig. 9. Displacement increment along the line of action calculation model with the eccentricity of driven gear at any transverse section; a) driving gear rotates counter-clockwise, and b) driving gear rotates clockwise
To determine that TE is caused only by the eccentricity of no-load TE, the no-load TE of counterclockwise and clockwise can be acquired when the displacement increment along the line of action translates into the rotational angle of the driven gear.

$$
\begin{aligned}
\Delta \varphi_{c c}= & \frac{180}{\pi R_{2} \cos \alpha} \times\left[e_{1} \sin \left(\varphi_{1 c c}+\theta_{1}+\alpha\right)\right. \\
& +e_{2} \sin \left(\varphi_{2 c c}+\theta_{2}-\alpha\right)-e_{1} \sin \left(\theta_{1}+\alpha\right) \\
& \left.-e_{2} \sin \left(\theta_{2}-\alpha\right)\right], \\
\Delta \varphi_{c}= & \frac{180}{\pi R_{2} \cos \alpha} \times\left[e_{1} \sin \left(\varphi_{1 c}-\theta_{1}+\alpha\right)\right. \\
& +e_{2} \sin \left(\varphi_{2 c}-\theta_{2}-\alpha\right)-e_{1} \sin \left(-\theta_{1}+\alpha\right) \\
& \left.-e_{2} \sin \left(-\theta_{2}-\alpha\right)\right],
\end{aligned}
$$

where $\Delta \varphi_{c c}$ is no-load TE of counter-clockwise rotation, $\Delta \varphi_{c}$ is no-load TE of clockwise rotation, and the unit is degree, and $R_{2}$ is the reference radius of driven gear.

\subsubsection{Theoretical Backlash Calculation}

The total backlash [39] of the gear pair can be divided into two components: the constant backlash (which is caused by factors including tooth thickness tolerance and allowance, and centre distance tolerance and allowance) and the variable backlash that is due mainly to the eccentricity. Therefore, the variable backlash can be calculated as follows [40]:

$$
\begin{aligned}
j_{v}= & \frac{180 \times 2 \tan \alpha}{\pi R_{2}} \times \\
& \quad\left[e_{2} \cos \left(\varphi_{2 c c}+\theta_{2}\right)-e_{1} \cos \left(\varphi_{1 c c}+\theta_{1}\right)\right],
\end{aligned}
$$

and, following that, the total backlash can be expressed as follows,

$$
j_{\varphi}=j_{v}+j_{c},
$$

where $j_{\varphi}, j_{v}, j_{v}$ are total backlash, variable backlash, and constant backlash respectively with the units in degrees.

Consequently, both no-load TE and backlash can be obtained via the eccentricity error and its initial phase. Therefore, it is first based on the experimental TE curve in order to obtain the eccentricity and its initial phase; then based on Eq. (21), the acquired eccentricity and initial phase, with the continuous backlash being obtained subsequently. 


\section{EXPERIMENTAL AND SIMULATION}

\subsection{Measurement of No-Load Torque TE and Backlash}

\subsubsection{The Test Rig}

The experiment used the incremental encoder ERN180 made by Heidenhain in Germany; the system accuracy is 18 arc seconds, the line number is 3600 , to output the $V_{P P}$ signal. Through the subdivision circuit matched with the encoder, the signal can be subdivided 20,25, and 50 times and output TTL signal. In this experiment, 25 times the subdivision is selected, the output pulses per second is 90,000 , and the resolution is 14.4 arc seconds.

The experimental test rig (Fig. 10) comprises a novel type of VTTIGP whose parameters are shown in Table 1 . The driving gear is fixed on the primary shaft, which is moved by a servo motor. The driven gear has been splined to its shaft and can be moved axially by a linear motor so that the value of the gear backlash can be modified by adjusting the relative position of the driven gear.

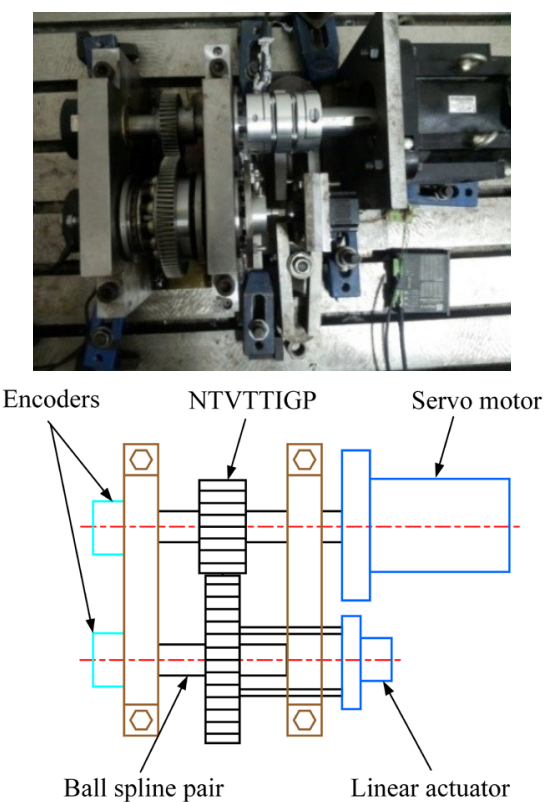

Fig. 10. Backlash control of the novel type of VTTIGP test rig

TE is measured by combining the absolute rotations of the two shafts as follows:

$$
\Delta \varphi=\varphi_{2}-\varphi_{1} \frac{z_{1}}{z_{2}},
$$

where $\varphi_{1}, \varphi_{2}$ are the angular displacement of driving gear and driven gear, respectively.
To achieve this, two incremental encoders were used as angular displacement sensors, which were fixed to the end of the two shafts, as shown in Fig. 10.

Table 1. Parameters of the novel type of VTTIGP

\begin{tabular}{|c|c|c|}
\hline Parameters & Driving gear & Driven gear \\
\hline Number of teeth & 45 & 80 \\
\hline Tip diameter [mm] & 94 & 164 \\
\hline Root diameter [mm] & 85 & 155 \\
\hline Module [mm] & 2 & 2 \\
\hline Tooth width [mm] & 20 & 20 \\
\hline Pressure angle $\left[^{\circ}\right]$ & 20 & 20 \\
\hline Helical angle $\left[{ }^{\circ}\right]$ & 3 & 3 \\
\hline Centre distance $[\mathrm{mm}]$ & 125.12 & \\
\hline Tooth thickness of the thinnest end [mm] & 2.093 & 2.093 \\
\hline Tooth thickness of the thickest end [mm] & 4.195 & 4.195 \\
\hline Transmission ratio & 1.778 & \\
\hline
\end{tabular}

\subsubsection{Measurement of TE}

The experimental TE curve is acquired when the driving gear rotates counter-clockwise at $60 \mathrm{rpm}$ at an angular displacement of 7560 degrees, then stops two seconds and finally backs to the initial position as shown in Fig. 11a. Fig. 11b shows the fitting TE curve based on the equation of no-load TE derived above and the experimental TE curve; the eccentricities and the initial phases of the novel type of VTTIGP can be obtained by the fitting method [38]. The acquired eccentricities and the initial phases of the driving and driven gear can be seen in Table 2. The obtained initial phases and the rotation displacements were recorded by the two recorders at the next start of the initial phases of the driving and driven gear so that it is not required to seek the initial phase of the gear pair again at each of the novel type of VTTIGP transmission start.

Table 2. Eccentricity and its initial phase of the novel type of VTTIGP

\begin{tabular}{lcc}
\hline Parameters & Driving gear & Driven gear \\
\hline Eccentricity [mm] & 0.0226 & 0.0273 \\
\hline Initial phase of eccentricity $\left[^{\circ}\right]$ & 49.5 & 79.3 \\
\hline
\end{tabular}

Despite the case of gear eccentric error values and phase determination, TE is a periodic function of the input gear corner and the output gear corner. However, when the input gear rotates at a uniform speed, ignoring the slight influence of the TE, the output gear can also be considered as rotating at a uniform speed, and the TE can be expressed as a function of gear speed and time. If the frequency spectrum analysis is 
performed on a TE curve obtained under a uniform rotation, the amplitudes of the input frequency and output frequency respectively reflect the eccentricity error of the two gears. In reference [41], it is based on this method to identify the gear eccentricity error.

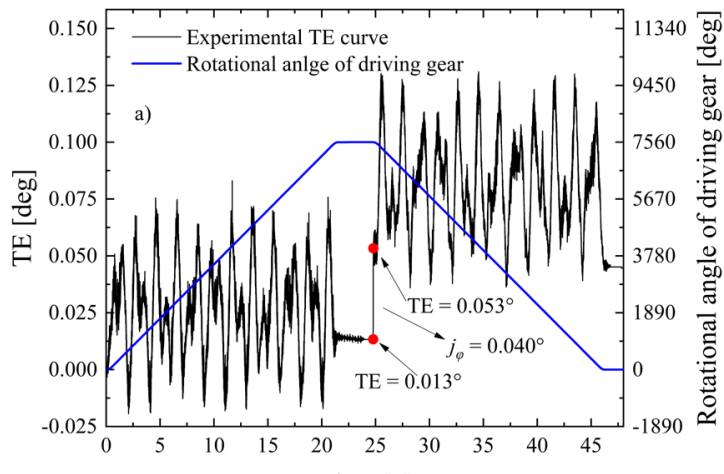

a)

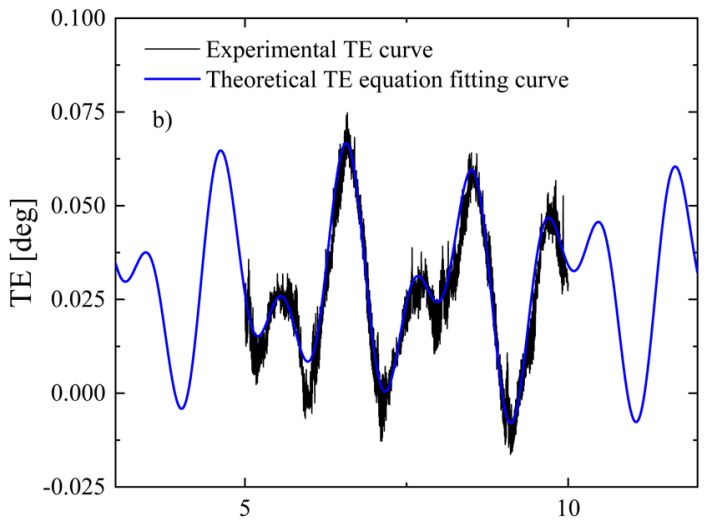

b)

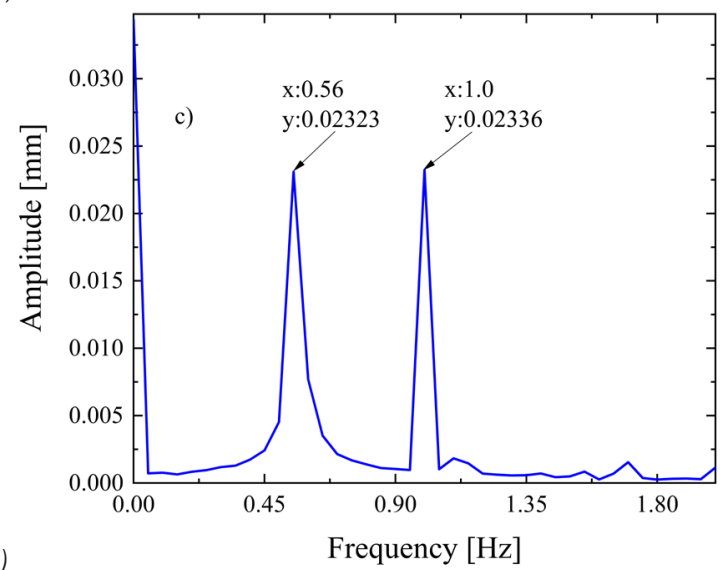

Fig. 11. TE measurement; a) experimental TE curve, b) theoretical TE equation fitting curve, and

c) experimental transmission error FFT diagram

Fig. 11c is an FFT diagram of the TE in the uniform speed section intercepted when the counterclockwise input speed is $60 \mathrm{rpm}$. It can be seen from the figure that the amplitudes corresponding to the rotation frequencies of the driving and driven gears are more consistent with the eccentricity values of the two gears obtained by the previous fitting, which proves the correctness of the eccentricity error obtained by the fitting.

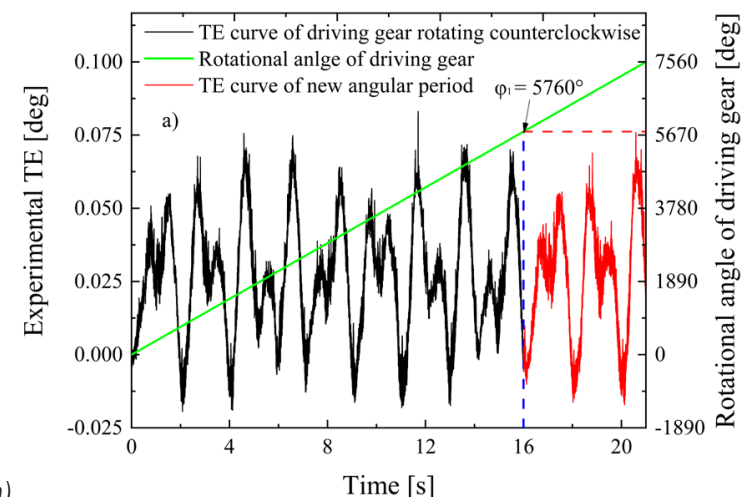

a)

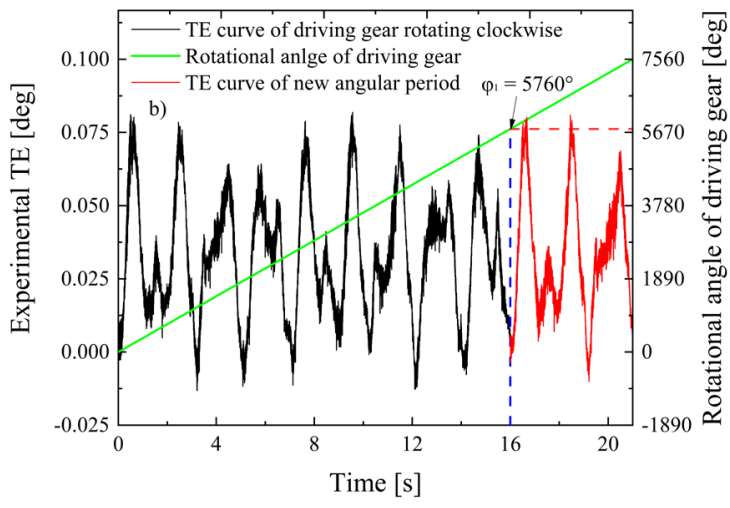

Fig. 12. Experimental TE at $60 \mathrm{rpm}$;

a) TE curve of driving gear rotating counter-clockwise, and b) TE curve of driving gear rotating clockwise

Since the two gears have 45 and 80 teeth, the driving gear's rotation of 5760 degrees is an angular period of the TE. Figs. 12a and $\mathrm{b}$ are the experimental TE curves when the driving gear rotates counterclockwise and clockwise at $60 \mathrm{rpm}$, respectively. It can be seen from the figures that when the driving gear rotates 5760 degrees, the new angular period of the TE starts, which proves the fundamental periodicity of Eqs. (19) and (20).

\subsubsection{Calculation and Measurement of Backlash}

The theoretical variable backlash of each position of the gear pair is obtained (as shown in Fig. 13) using Eq. (21) and the obtained eccentricities and the initial phases (as shown in Table 1). Additionally, the constant backlash of gear pair can be obtained using Eq. (22), which is based on the total backlash value 
when the driving wheel is reversed at the position of 7560 degrees as shown in Fig. 11a and the variable backlash at the position of 7560 degrees as calculated by Eq. (21). Therefore, the theoretical total backlash curve of the gear can be obtained by adding the constant backlash curve and the variable backlash curve.

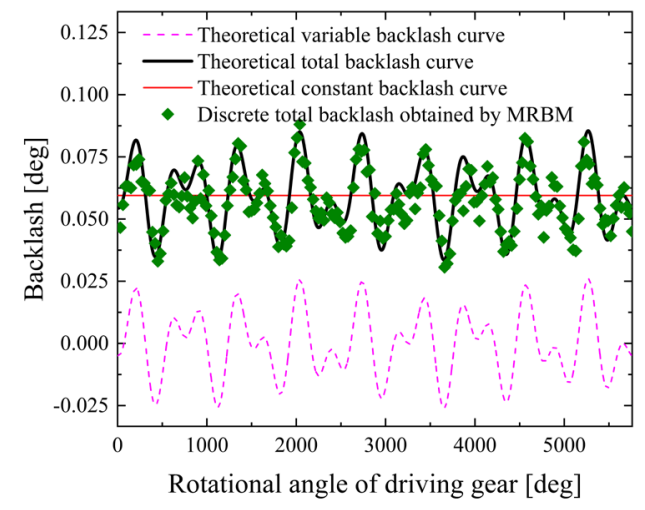

Fig. 13. Backlash results comparison of the novel type VTTIGP
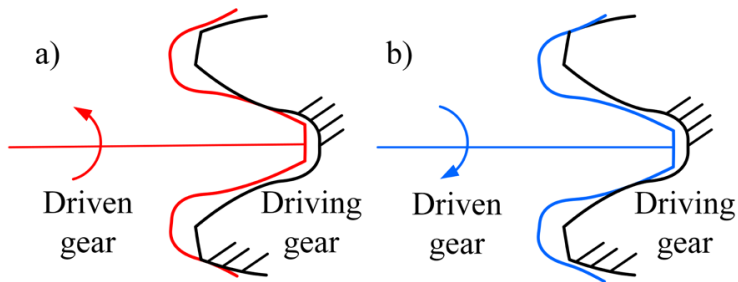

Fig. 14. Mechanical return backlash method; a) the driven gear rotates counter-clockwise, and b) the driven gear rotates clockwise

In order to verify the obtained theoretical total backlash curve, the mechanical return backlash method (MRBM), which is obtained by fixing the driving gear at a specified position and then rotating the driven gear clockwise and counter-clockwise (as shown in Fig. 14) is used to calculate the angle difference that is equal to the backlash of the specified position of the driving gear. The results show that the backlash curve obtained by the theoretical equation agrees with the backlash value by MRBM.

In summary, the axial displacement to eliminate backlash can be calculated when the gear pair has a reverse motion based on the acquired total backlash and Eq. (16).

\subsection{Backlash Control of Simulation Verification}

The mechanical and control co-simulation model of the novel type of VTTIGP was established in RecurDyn (as shown in Fig. 15), whose gear parameters are consistent with those in Table 1. Simultaneously, a revolute joint is constructed at the eccentric position of the driving gear, and a rotating and axial moving constraint is set up at the eccentric position of the driven gear. The solid contact of the gear pair is also established. Moreover, the input speed of the driving gear is set to $100 \mathrm{rpm}$, and the driving gear will stop at 7524 degrees and then back to the initial position. Additionally, the external loads include the friction of the revolution joints and the inertia force of the gear pair. Finally, according to the control mode shown in Fig. 7, a simulation control program was established in Colink, as shown in Fig. 15. In order to better show the effect of backlash, the gear pair will stop some seconds when the driving gear is reversed.

Fig. 16 shows the results of the simulation TE curve with and without backlash control. It can be seen that the TE curve without backlash control has a jump when the driving gear is reversed, and the jump value is equal to the backlash at the reverse position. However, in the TE curve with backlash control, the

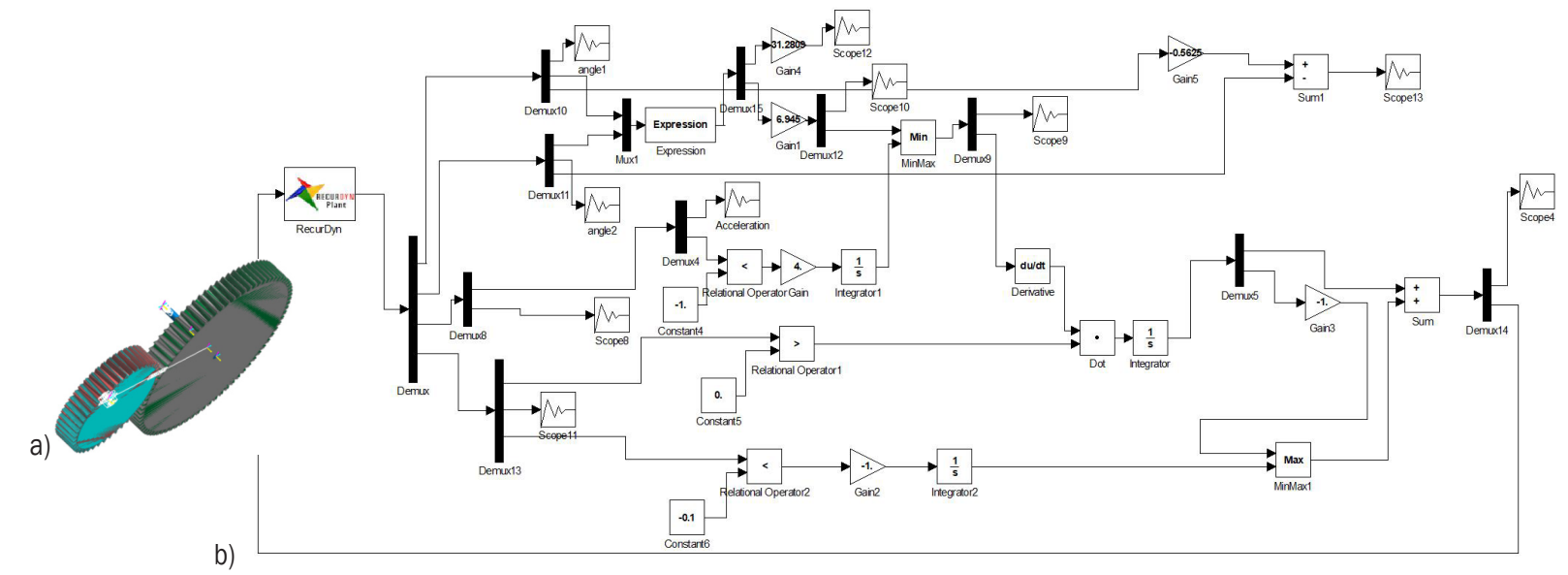

Fig. 15. a) VTTGP and b) its backlash control simulation model 
jump phenomenon is not obvious, which demonstrates that the backlash has been controlled effectively.

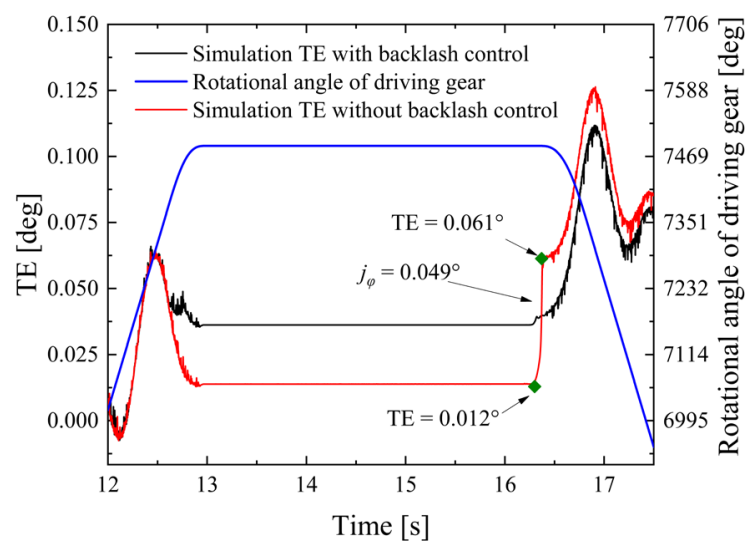

Fig. 16. Simulation TE curve with and without backlash control

\section{RESULTS AND DISCUSSION}

\subsection{Comparative Study on Backlash Control through Experimental and Simulation Method}

\subsubsection{Experimental Anti-Backlash Method}

As Fig. 7 shows, during gear transmission, the backlash controller receives the angular displacement signal of the encoder of the driving gear in real time and determines whether the speed is reduced or not. When the deceleration signal is detected, according to the current angular displacement signal, the controller calculates the corresponding backlash value and the axial displacement of driven gear required for eliminating backlash. The linear actuator will then receive a signal from the controller to move the driven gear to the specified axial position for anti-backlash. Finally, when the controller detects the acceleration signal of the driving gear, the linear actuator returns to its original axial position.

\subsubsection{Backlash Control Comparison and Validation}

Due to the output part in the application needed to eliminate backlash always having a relatively low speed, the speed of the experiment in this paper is carried out at a relatively low level. Figs. 17 to 20 show the simulation and experimental TE curves of the novel type of VTTIGP with and without backlash control at different reverse positions under different input speeds. According to the encoder signal, the driving gear will return to the initial rotational position after each experimental measurement and then rotate a large period cycle (a large period cycle is defined as that where the driving gear rotates 5760 degrees), which ensures the initial phases of both the driving and driven gear are the same as the parameters in Table 1.

In the figures below, the simulation and experimental TE curves agree well with each other demonstrating that the co-simulation model of the novel type of VTTIGP is consistent with the experimental rig. Due to the eccentricity of the gear pair, the backlash values will not be the same at the different reverse positions when the novel type of VTTIGP is without backlash control, so that the jump values in the TE curve vary, as shown in Figs. 17a, 18a, 19a, and 20a. However, after backlash control, the jump phenomenon in the TE curve improves in each experiment (as shown in Figs. 17b, 18b, 19b, and $20 \mathrm{~b}$ ), which verifies the validation of the eliminating backlash device and the anti-backlash control mode.
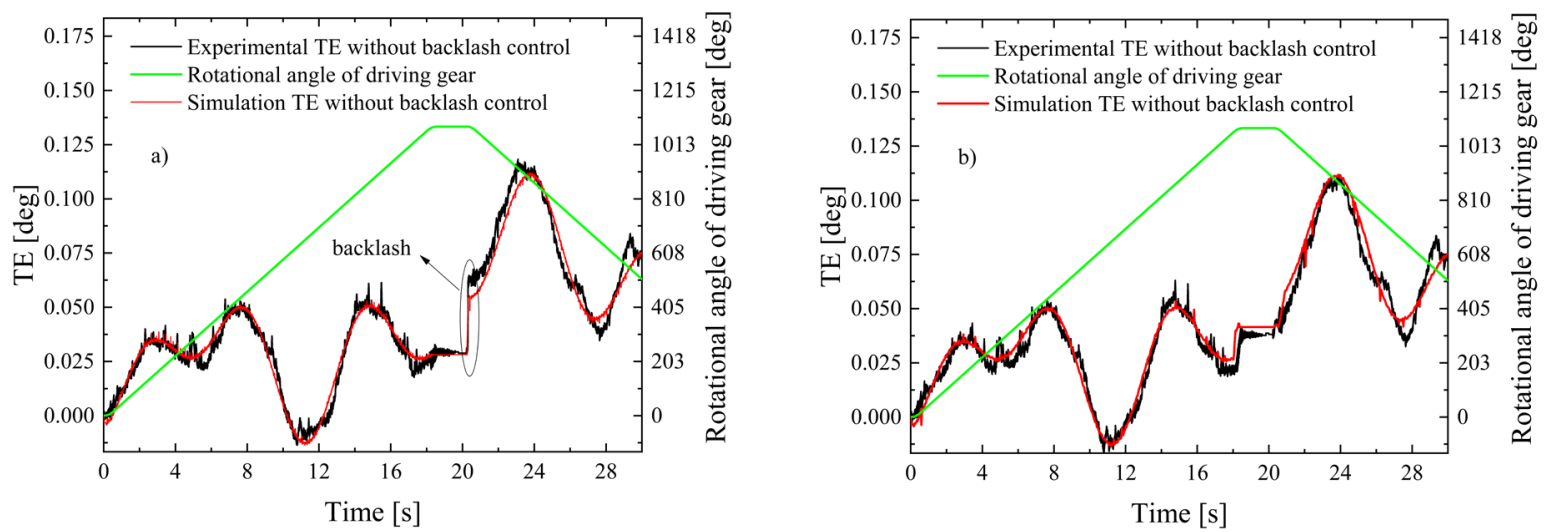

Fig. 17. TE measurement with input speed of $10 \mathrm{rpm}$ and reversed position of 1080 degrees of driving gear; a) without backlash control, and b) with backlash control 

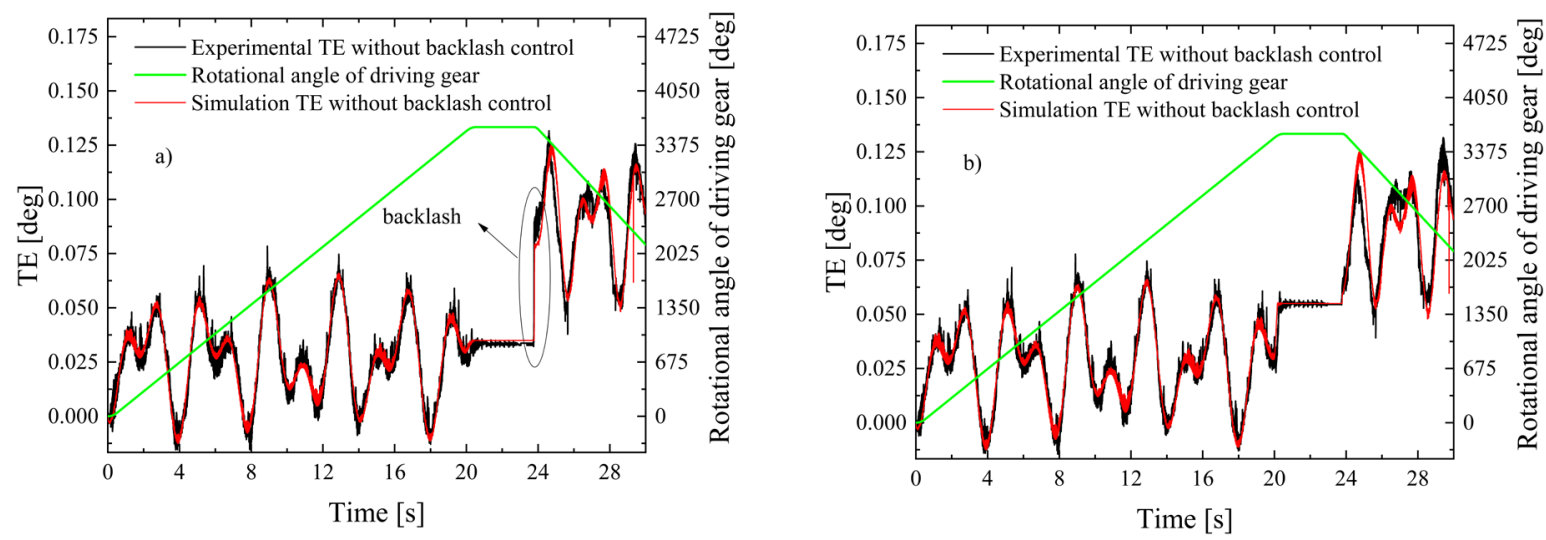

Fig. 18. TE measurement with input speed of $30 \mathrm{rpm}$ and reversed position of 3600 degrees of driving gear;

a) without backlash control, and b) with backlash control
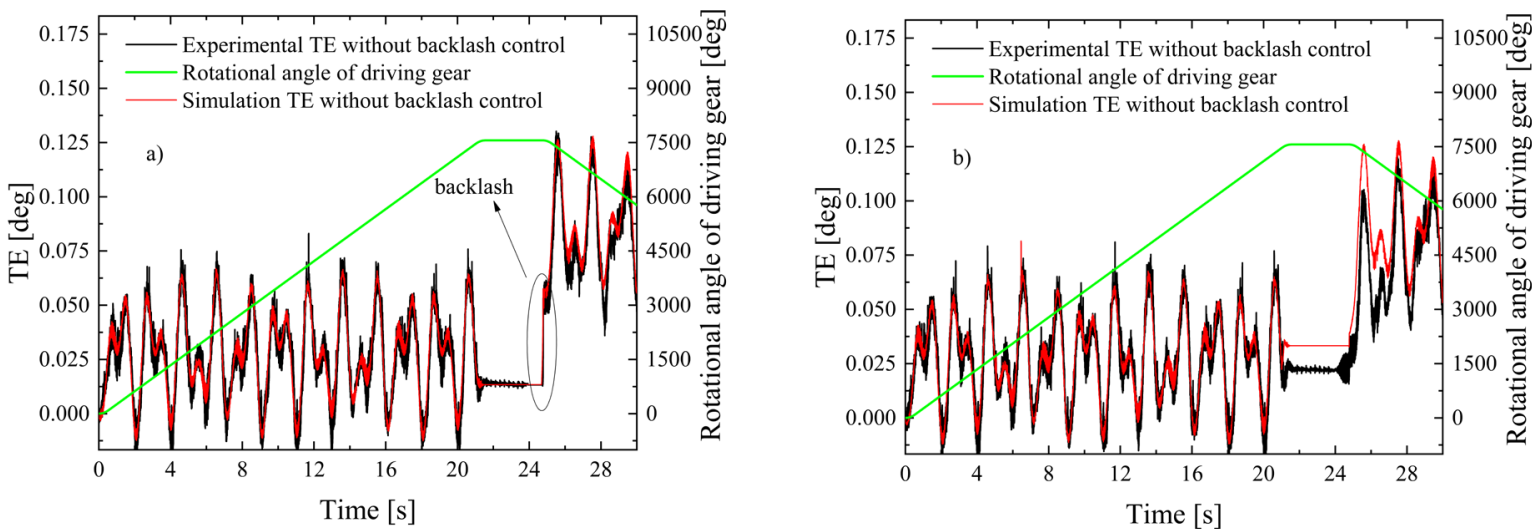

Fig. 19. TE measurement with input speed of $60 \mathrm{rpm}$ and reversed position of 7560 degrees of driving gear;

a) without backlash control, and b) with backlash control
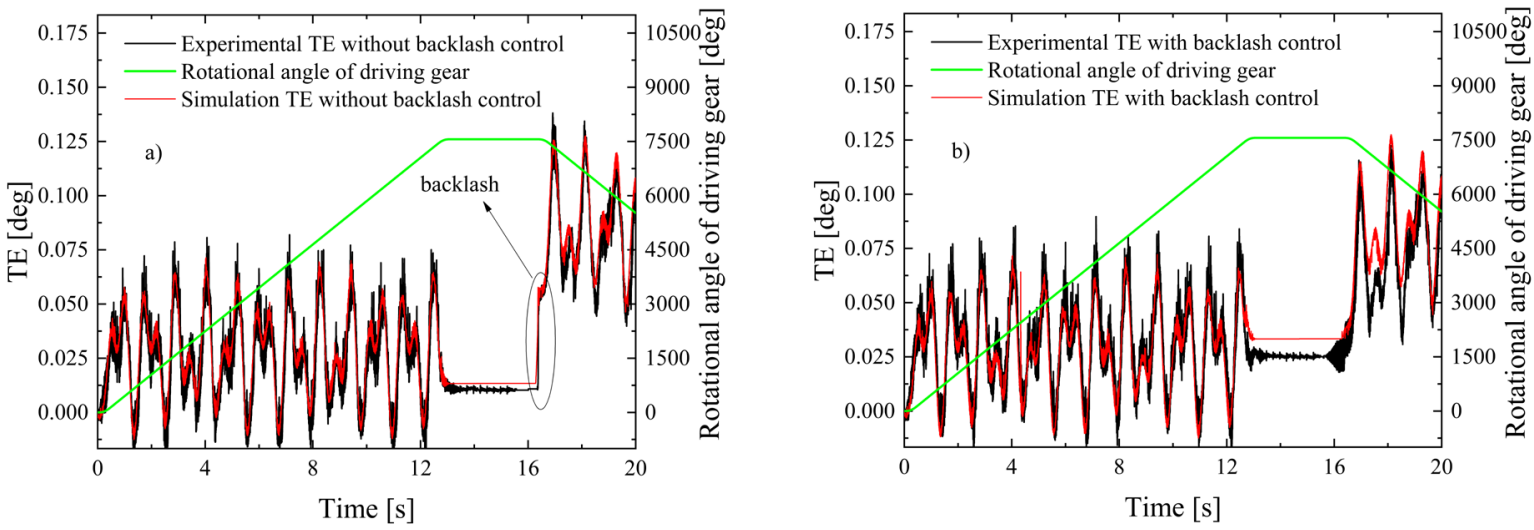

Fig. 20. TE measurement with input speed of $100 \mathrm{rpm}$ and reversed position of 7560 degrees of driving gear; a) without backlash control, and b) with backlash control

\subsection{Comparison of Transmission Error with and without Backlash Control}

According to the TE curves measured by all the above simulations and experiments, the average value, maximum value, minimum value, and backlash are compared, as shown in Table 3.

It is easy to know that the average, maximum, and minimum values of the TE with and without the backlash control are relatively consistent, while the 
instantaneous backlash is significantly reduced after the backlash control. Therefore, it can be seen that the instantaneous backlash control can reduce the TE at a certain time after the backlash control, and the transmission process is more stable, which proves the effectiveness of the electronically controlled anti-backlash mechanism. Since this article aims to realize and verify the anti-backlash function of the electronically controlled anti-backlash mechanism, the machining and assembly accuracy of gears and other parts adopts ordinary accuracy (gear accuracy is 7 levels). Therefore, in the entire transmission process with and without the backlash control, the main factor that affects the large-period TE is the eccentricity error.

Table 3. Comparison of TE with and without backlash control

\begin{tabular}{|c|c|c|c|c|c|c|}
\hline \multirow{2}{*}{$\begin{array}{l}\text { Rotating } \\
\text { speed }\end{array}$} & \multirow{2}{*}{\multicolumn{2}{|c|}{ Backlash control }} & \multicolumn{3}{|c|}{$\mathrm{TE}\left[^{\circ}\right]$} & \multirow{2}{*}{$\begin{array}{c}\text { Backlash } \\
{\left[{ }^{\circ}\right]}\end{array}$} \\
\hline & & & Avg & Max & Min & \\
\hline \multirow{4}{*}{10 rpm } & \multirow{2}{*}{ With } & Experiment & 0.0412 & 0.1117 & 0.016 & - \\
\hline & & Simulation & 0.0427 & 0.1118 & -0.0135 & - \\
\hline & \multirow{2}{*}{$\begin{array}{l}\text { With } \\
\text { out }\end{array}$} & Experiment & 0.0425 & 0.1183 & -0.0136 & 0.0342 \\
\hline & & Simulation & 0.0419 & 0.1121 & -0.0135 & 0.0262 \\
\hline \multirow{4}{*}{30 rpm } & \multirow{2}{*}{ With } & Experiment & 0.0437 & 0.1316 & -0.0145 & - \\
\hline & & Sims & 0.0 & 0.1253 & -0.0 & - \\
\hline & \multirow{2}{*}{$\begin{array}{l}\text { With } \\
\text { out }\end{array}$} & Experiment & 0.0 & 0.1 & -0.0154 & 0.0471 \\
\hline & & Simulation & 0.0 & 0.1253 & -0.0 & 0.0443 \\
\hline \multirow{4}{*}{60 rpm } & \multirow{2}{*}{ With } & Experiment & 0.0345 & 0.1228 & -0.0175 & - \\
\hline & & Simulation & 0.0385 & 0.1278 & -0.0120 & - \\
\hline & \multirow{2}{*}{$\begin{array}{l}\text { With } \\
\text { out }\end{array}$} & Experiment & 0.0347 & 0.1302 & -0.0194 & 0.0412 \\
\hline & & Simulation & 0.0362 & 0.1279 & -0.0126 & 0.0443 \\
\hline \multirow{4}{*}{$100 \mathrm{rpm}$} & \multirow{2}{*}{ With } & Experiment & 0.0368 & 0.1224 & -0.018 & - \\
\hline & & Simulation & 0.0387 & 0.1275 & -0.0125 & - \\
\hline & \multirow{2}{*}{$\begin{array}{l}\text { With } \\
\text { out }\end{array}$} & Experiment & 0.0331 & 0.1381 & -0.0213 & 0.0437 \\
\hline & & Simulation & 0.0356 & 0.1276 & -0.0126 & 0.0436 \\
\hline
\end{tabular}

\section{CONCLUSIONS}

(1) This paper has presented an electrical backlash control method based on the novel type of VTTIGP. According to the angular acceleration and angular displacement of the driving gear, backlash elimination can be realized at the time of reversal by adjusting the relative axial displacement between the driving and driven gear.

(2) The continuous theoretical backlash curve was attained through the eccentricity and its initial phase of the novel type of VTTIGP, which can be obtained by fitting the experimental TE curve through the developed no-load TE equation. Comparing the theoretical backlash to the experiment one, it can be seen that the backlash curve obtained by the theoretical equation agrees with the backlash value determined by MRBM.

(3) An experimental backlash control investigation was also carried out, which showed that under different input speeds and at various reverse positions, the TE curves without backlash control both have a jump phenomenon at the time of reverse; however, after backlash control, the jump phenomenon in TE curves improves. This demonstrates that this backlash control method can eliminate backlash effectively at the time of reversal. Additionally, the TE curves of the simulation and experiment agreed well with each other, which indicates that the constructed co-simulation model of the novel type of VTTIGP is consistent with the experimental rig.

The conclusion shows that under no-load conditions, the theory and experiment have achieved good agreement. However, the load has a certain effect on the backlash. Therefore, it is necessary to establish the backlash control model of the novel type of VTTIGP under load and carry out related experimental research. More related topics will be discussed in the follow-up.

\section{ACKNOWLEDGEMENTS}

This work is supported by the National Natural Science Foundation of China (Grant No. 92048201) and the Fundamental Research Funds for the Central Universities (Project No.2021CDJJMRH-008). The authors thank the reviewer for his/her valuable comments on the manuscript.

\section{REFERENCES}

[1] Wang, G., Chen, L., Yu, L., Zou, S. (2017). Research on the dynamic transmission error of a spur gear pair with eccentricities by finite element method. Mechanism and Machine Theory, vol. 109, p. 1-13, D0l:10.1016/j. mechmachtheory.2016.11.006.

[2] Wang, G., Su, L., Zou, S. (2020). Uneven load contact dynamic modelling and transmission error analysis of a $2 \mathrm{~K}-\mathrm{V}$ reducer with eccentricity excitation. Strojniški vestnik Journal of Mechanical Engineering, vol. 66, no. 2, p. 91-104, DOI:10.5545/sv-jme.2019.6298.

[3] Yang, Q., Liu, T., Wu, X., Deng, Y., Chen, Q. (2021). A planetary gear reducer backlash identification based on servo motor current signal and optimized fisher discriminant analysis. ISA Transaction, vol. 112, p. 350-362, D0I:10.1016/j. isatra.2020.12.016.

[4] Liu, W., Zhao, H., Lin, T., Gao, B., Yang, Y. (2020). Vibration characteristic analysis of gearbox based on dynamic excitation with eccentricity error. Journal of Mechanical Science and 
Technology, vol. 34, p. 4545-4562, D0l:10.1007/s12206-0201014-6.

[5] Ren, X., Li, D., Sun, G., Zhao, W. (2016). Eso-based adaptive robust control of dual motor driving servo system. Asian Journal of Control, vol. 18, n. 6, p. 2358-2365, D0l:10.1002/ asjc.1325.

[6] Dong, R., Tan, Y., Chen, H. (2009). Recursive identification for dynamic systems with backlash. Asian Journal of Control, vol. 12, no. 1, p. 26-38, D0l:10.1002/asjc.157.

[7] Warnecke, M., Jouaneh, M. (2003). Backlash compensation in gear trains by means of open-loop modification of the input trajectory. Journal of Mechanical Design, vol. 125, no. 3, p. 620-624, DOI:10.1115/1.1596241.

[8] Yang, Q., Liu, T., Wu, X., Deng, Y. (2020). Gear backlash detection and evaluation based on current characteristic extraction and selection. IEEE Access, vol. 8, p. 107161107176, DOI:10.1109/access.2020.2999478.

[9] Yu, C. (2016). Analysis and study on eliminating clearance structure of mechanical precision transmission. Mechanical Research \& Application, vol. 29, no. 1, p. 8-11. (in Chinese)

[10] Nordin, M., Gutman, P.-0. (2002). Controlling mechanical systems with backlash-a survey. Automatica, vol. 38, no. 10, p. 1633-1649, D0l:10.1016/s0005-1098(02)00047-x.

[11] Michaelec, G.W. (1966). Precision Gearing-Theory and Practice. John Wiley \& Sons, New York.

[12] Beam, A.S. (1954). Beveloid gear. Machine Design, vol. 26, no. 12 , p. 220-238.

[13] Chen, Q., Song, C., Zhu, C., Du, X., Ni, G. (2017). Manufacturing and contact characteristics analysis of internal straight beveloid gear pair. Mechanism and Machine Theory, vol. 114, p. 60-73, D0l:10.1016/j.mechmachtheory.2017.04.002.

[14] Sun, R., Song, C., Zhu, C., Yang, X., Li, X. (2021). Computational study of pitting defect influence on mesh stiffness for straight beveloid gear. Engineering Failure Analysis, vol. 119, p. 1-15, D0l:10.1016/j.engfailanal.2020.104971.

[15] Do, T.P., Ziegler, P., Eberhard, P. (2015). Review on contact simulation of beveloid and cycloid gears and application of a modern approach to treat deformations. Mathematical and Computer Modelling of Dynamical Systems, vol. 21, no. 4, p. 359-388, DOl:10.1080/13873954.2015.1012838.

[16] Yang, X., Song, C., Zhu, C., Liu, S. (2018). Tooth surface deviation and mesh analysis of beveloid gears with parallel axis considering machine tool adjustment errors. Journal of Advanced Mechanical Design, Systems, and Manufacturing, vol. 12, no. 4, p. 1-15, D0l:10.1299/jamdsm.2018 jamdsm0082.

[17] Cao, B., Li, G. (2021). Computerized design of plunge shaving tool for beveloid gears and plunge shaving characteristic analysis. Mechanism and Machine Theory, vol. 161, p. 1-16, D0I:10.1016/j. mechmachtheory.2021.104325.

[18] Brauer, J. (2005). Transmission error in anti-backlash conical involute gear transmissions: A global-local fe approach. Finite Elements in Analysis and Design, vol. 41, no. 5, p. 431-457, DOl:10.1016/j.finel.2004.04.007.

[19] Song, C., Zhou, S., Zhu, C., Yang, X., Li, Z., Sun, R. (2018). Modeling and analysis of mesh stiffness for straight beveloid gear with parallel axes based on potential energy method. Journal of Advanced Mechanical Design, Systems, and Manufacturing, vol. 12, no. 7, p. 1-14, D0l:10.1299/ jamdsm.2018jamdsm0122.

[20] Sun, R., Song, C., Zhu, C., Wang, Y., Yang, X. (2020). Computational studies on mesh stiffness of paralleled helical beveloid gear pair. International Journal of Precision Engineering and Manufacturing, vol. 22, no. 1, p. 123-137, DOl:10.1007/s12541-020-00452-3.

[21] Li, G., Wu J., Li H. (2000). Design and calculation of parallel shaft internal meshing beveloid gear. Chinese Mechanical Engineering, vol. 8, no.11, p. 886-889. (in Chinese)

[22] Yan, H., Huang, Q., Xing, J., Zhou, F. (2017). The analysis of the efficiency of $3 \mathrm{~K}$ type conical involute planetary gears transmission reducer. Machinery Design \& Manufacture, vol. 5, p. 158-161. (in Chinese)

[23] Zheng, Z., Chen, Y., Chen, B., Du, X., Li, C. (2020). Meshing performance investigations on a novel point-contact hourglass worm drive with backlash-adjustable. Mechanism and Machine Theory, vol. 149, p. 1-17, D0l:10.1016/j. mechmachtheory.2020.103841.

[24] Ye, X., Chen, Y., Lu, B., Luo, W., Chen, B. (2022). Study on a novel backlash-adjustable worm drive via the involute helical beveloid gear meshing with dual-lead involute cylindrical worm. Mechanism and Machine Theory, vol. 167, p. 1-21, DOI:10.1016/j.mechmachtheory.2021.104466.

[25] Tsai, L. W., Chang, S.L. (1994). Backlash control via redundant drives: An experimental verification. Journal of Mechanical Design, vol. 116, no. 3, p. 963-967, D0l:10.1115/1.2919477.

[26] dos SantosCoelho, L., Cunha, M.A.B. (2011). Adaptive cascade control of a hydraulic actuator with an adaptive dead-zone compensation and optimization based on evolutionary algorithms. Expert Systems with Applications, vol. 38, n. 10, p. 12262-12269, D0l:10.1016/j.eswa.2011.04.004.

[27] Rostalski, P., Besselmann, T., Barić, M., Belzen, F. V., Morari, M. (2007). A hybrid approach to modelling, control and state estimation of mechanical systems with backlash. International Journal of Control, vol. 80, n. 11, p. 1729-1740, DOI:10.1080/00207170701493985.

[28] Na, J., Ren, X., Herrmann, G., Qiao, Z. (2011). Adaptive neural dynamic surface control for servo systems with unknown dead-zone. Control Engineering Practice, vol. 19, no. 11, p. 1328-1343, D0I:10.1016/j.conengprac.2011.07.005.

[29] Shi, Z., Zuo, Z. (2015). Backstepping control for gear transmission servo systems with backlash non-linearity. IEEE Transactions on Automation Science and Engineering, vol. 12, no. 2, p. 752-757, DOl:10.1109/tase.2014.2369430.

[30] Sato, K., Murayama, Y., Imada, S., Shimokohbe, A. (1995). Control and elimination of lead screw backlash for ultraprecision positioning. JSME International Journal. Ser. C, Dynamics, Control, Robotics, Design and Manufacturing, vol. 38, no. 1, p. 36-41, D0I:10.1299/jsmec1993.38.36.

[31] Chen, W., Wu, Y., Du, R., Wu, X. (2014). Fault diagnosis and fault tolerant control for the servo system driven by two motors synchronously. Control Theory \& Application, vol. 31, no. 1, p. 27-34. (in Chinese)

[32] Zhang, Z., Peng, C., Shao, S. (2017). A Rotation speed offset regulation and model predictive control based anti-backlash control approach for dual motor servo system, MICROMOTORS, vol. 50 , no. 1, p. 54-58. (in Chinese) 
[33] Jiang, Y., Zhang, W., Liu, X., Jin, B. (2020). simulation and application of anti-backlash technique with dual motor in tandem manipulators. China Mechanical Engineering, vol. 31, no. 16, p. 1991-1997. (in Chinese)

[34] Litvin, F.L. (2008). Gear Geometry and Applied Theory. Shanghai Science and Technology Press, Shanghai.

[35] Wu, X.T. (1982). Gear Meshing Principle. Machinery Industry Press, China.

[36] Tao, L. (2005). Performance comparison analysis of stepped double involute gear and ordinary involute gear. Chongqing University, Chongqing.

[37] Yu, L., Wang, G., Zou, S. (2017). The calculation of meshing efficiency of a new type of conical involute gear. Strojniški vestnik - Journal of Mechanical Engineering, vol. 63, no. 5, p. 320-330, D0I:10.5545/sv-jme.2016.3843.
[38] Yu, L., Wang, G., Zou, S. (2018). The experimental research on gear eccentricity error of backlash-compensation gear device based on transmission error. International Journal of Precision Engineering and Manufacturing, vol. 19, p. 5-12, DOl:10.1007/s12541-018-0001-7.

[39] Michalec, G.W. (1973). Correlation of probabilistic backlash with measurements. Mechanism and Machine Theory, vol. 8 , no. 2, p. 161-173, D0I:10.1016/0094-114x(73)90050-5.

[40] Wu, C. (1982). Research on transmission error by eccentric gear. Journal of Nanjing Institute of Technology, vol. 4, p. 133145. (in Chinese)

[41] Rocca, E., Russo, R. (2011). Theoretical and experimental investigation into the influence of the periodic backlash fluctuations on the gear rattle. Journal of Sound and Vibration, vol. 330, no. 20, p. 4738-4752, D0l:10.1016/j. jsv.2011.04.008. 